\title{
Intense blue light therapy during the night-time does not suppress the rhythmic melatonin biosynthesis in a young boy
}

\author{
${ }^{1}$ Stebelova K, ${ }^{2}$ Kosnacova J, ${ }^{1}$ Zeman M \\ ${ }^{1}$ Department of Animal Physiology and Ethology, Faculty of Natural Sciences, Comenius University, \\ Bratislava, Slovak Republic; \\ ${ }^{2} 1^{\text {st }}$ Department of Pediatrics, University Children's Hospital, Bratislava, Slovak Republic \\ E-mail:stebelova@fns.uniba.sk
}

Objective. Melatonin is a hormone predominantly synthesized and secreted during the night by the pineal gland. Artificial light at night, especially its blue part, acutely suppresses the melatonin production. The aim of the present study was to find out, whether an intense blue light phototherapy of severe hyperbilirubinemia, may suppress the melatonin production during the night when the eyes will be properly protected by a sleep mask.

Methods. The main melatonin metabolite, 6-sulphatoxymelatonin was measured in urine in a nine-year old boy suffering from the Crigler-Najjar syndrome type I. The boy was treated during the sleep period with an intense blue light (to $1800 \mathrm{~lx}$ ) $10 \mathrm{~h}$ /day, since his birth. During the phototherapy, his eyes were protected with a sleep mask. The concentration of 6-sulphatoxymelatonin was determined in the first morning urine and urine collected afternoon during the six days. The patient was exposed to phototherapy for three nights, two nights without and the last one with the treatment. The control urine samples were obtained from 8 healthy nine-year old boys. The level of 6-sulphatoxymelatonin was measured by radioimmunoassay and the data were normalized to urinary creatinine.

Results. A distinct melatonin production rhythm was found and 6-sulphatoxymelatonin concentration in urine of the patient was comparable with the values obtained by the control group. No differences in 6-sulphatoxymelatonin levels were found between the nights with and without the phototherapy applied.

Conclusions. We conclude that the whole night treatment of hyperbilirubinemia with intense blue light has negligible side effect on the rhythmic melatonin production, when the eyes are sufficiently protected by the sleep mask.

Key words: melatonin, 6-sulphatoxymelatonin, phototherapy, blue light, hyperbilirubinemia

Melatonin is a dark-time hormone, biosynthesized in the pineal gland exclusively during the night. Its production is under the circadian control of the master circadian oscillator localized in the hypothalamic suprachiasmatic nucleus. The melatonin production in the night can be effectively suppressed by a light (Bojkowski et al. 1987a; McIntyre et al. 1989). The suppressive effect of the light depends on its duration, intensity, and wavelength. The shorter light wavelengths, corresponding to the blue light, induce stronger melatonin suppression (Brainard et al. 2008; West et al. 2011).

Corresponding author: Katarina Stebelova, PhD., Department of Animal Physiology and Ethology, Faculty of Natural Sciences, Comenius University in Bratislava, Ilkovicova 6, 84215 Bratislava, Slovak Republic; phone: +421 260296403 ; 


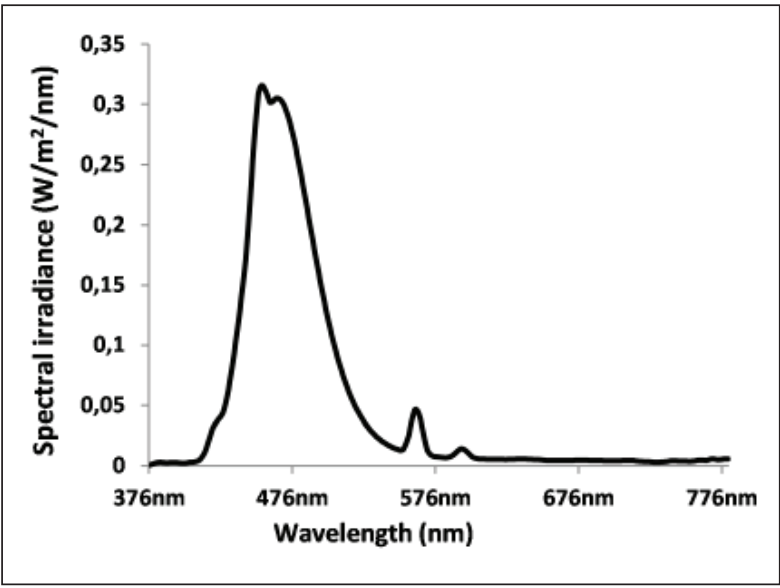

Figure 1. Spectral irradiance of fluorescent lamps used for the phototherapy of Crigler-Najjar syndrome type I.

Melatonin has pleiotropic effects acting at different levels of the human physiology (Hardeland et al. 2011). Therefore, the decreased melatonin production can be related to different pathological situations and requires a specific attention.

The blue light therapy successfully reduces the serum bilirubin levels in the jaundiced neonates suffering from hyperbilirubinemia. The Crigler-Najjar syndrome type I is a recessively inherited disorder characterized by an absence of hepatic uridine 5 '-diphospho-glucuronosyltransferase. The activity of this enzyme is essential for the conjugation and excretion of the bilirubin. Patients with this syndrome suffer from severe unconjugated hyperbilirubinemia and children are exposed to a phototherapy with an intense blue light (wavelength around $440 \mathrm{~nm}$ ) for 10 h/day since their birth (Fox et al. 1998).

It is not known whether eye protection during the exposure to intense blue light is sufficient to preclude a nocturnal suppression of the melatonin production. Therefore, the aim of this study was to establish the 6-sulphatoxymelatonin levels in urine of a young boy suffering from the severe hyperbilirubinemia caused by the Crigler-Najjar syndrome type I treated by an intense blue light during the sleep period.

\section{Materials and Methods}

The nine-year old boy with the Crigler-Najjar syndrome type I was treated with an intense blue light every night since his birth. During the phototherapy, the illuminance at the position of his head in the bed was approximately $1800 \mathrm{~lx}$ with a domi- nant wavelength between $430-460 \mathrm{~nm}$ (Figure 1) as measured by the illuminance spectrophotometer CL500A, Konica Minolta, Japan. During the sleeping period, his eyes were covered by a sleep mask. Eight age-matched boys were used as a control group. They were without any medication and slept in the dark.

The informed consent was obtained after detailed explanation of the study from all parents of the participating children. The study conformed to the code of the ethics stated in the Declaration of Helsinki.

The concentration of 6-sulphatoxymelatonin (aMT6s) in urine was measured for 6 days. The patient was exposed to blue light for three nights, next two nights was without phototherapy and the last night was exposed again to the blue light. Urine samples were collected every day immediately after waking up (approximately at 6:30) and at the end of the active phase at 20:00 h. The urine samples of the control boys were collected from the first morning urine and the afternoon urine of the same day. All the samples were stored at $-18^{\circ} \mathrm{C}$ until analyzed.

The concentration of aMT6s in urine was determined by direct radioimmunoassay using a commercially available kit (Stockgrand Ltd, Guildford, UK) according to the manufacturer instructions. The samples were measured within four assays, inter-assay coefficients were $4.75 \%, 5.03 \%$ and $10.32 \%$ for low, medium, and high quality control samples, respectively. Mean intra-assay coefficient of variation was $11.23 \%$. Creatinine was assayed in every sample (BioLaTest, ErbaLachema, Czech Republic). The results are expressed as aMT6s/creatinine (ng/mg).

\section{Results and Discussion}

Concentrations of aMT6s/creatinine in the first morning urine of the blue light treated patient were in the range of control probands. In the first patient urine, the aMT6s/creatinine concentrations were in the range from 86 to $200 \mathrm{ng} / \mathrm{mg}$ after whole night treatment with the blue light (Figure $2 \mathrm{~A} / \mathrm{a}, \mathrm{c}$ ) and 87 $\mathrm{ng} / \mathrm{mg}$ and $147 \mathrm{ng} / \mathrm{mg}$ after nights spent in the dark (Figure $2 \mathrm{~A} / \mathrm{b}$ ). In the control group, the aMT6s/creatinine levels ranked from 47 to $220 \mathrm{ng} / \mathrm{mg}$ with average concentration of $100.11 \pm 27.05 \mathrm{ng} / \mathrm{mg}$ (Figure $2 \mathrm{~B}$ ).

As expected, the levels of the melatonin metabolite were low during the day-time. The average day-time concentration of aMT6s/creatinine was $3.73 \pm 0.97$ $\mathrm{ng} / \mathrm{mg}$ at the end of the day after night with phototherapy (Figure $2 \mathrm{~A} / \mathrm{a}, \mathrm{c}$ ) and $4.76 \pm 0.96 \mathrm{ng} / \mathrm{mg}$ at the end of the day after nights spent in the dark. Mean day-time aMT6s/creatinine levels were $6.95 \pm 2.45$ $\mathrm{ng} / \mathrm{mg}$ in urine of the control group (Figure 2/B). 


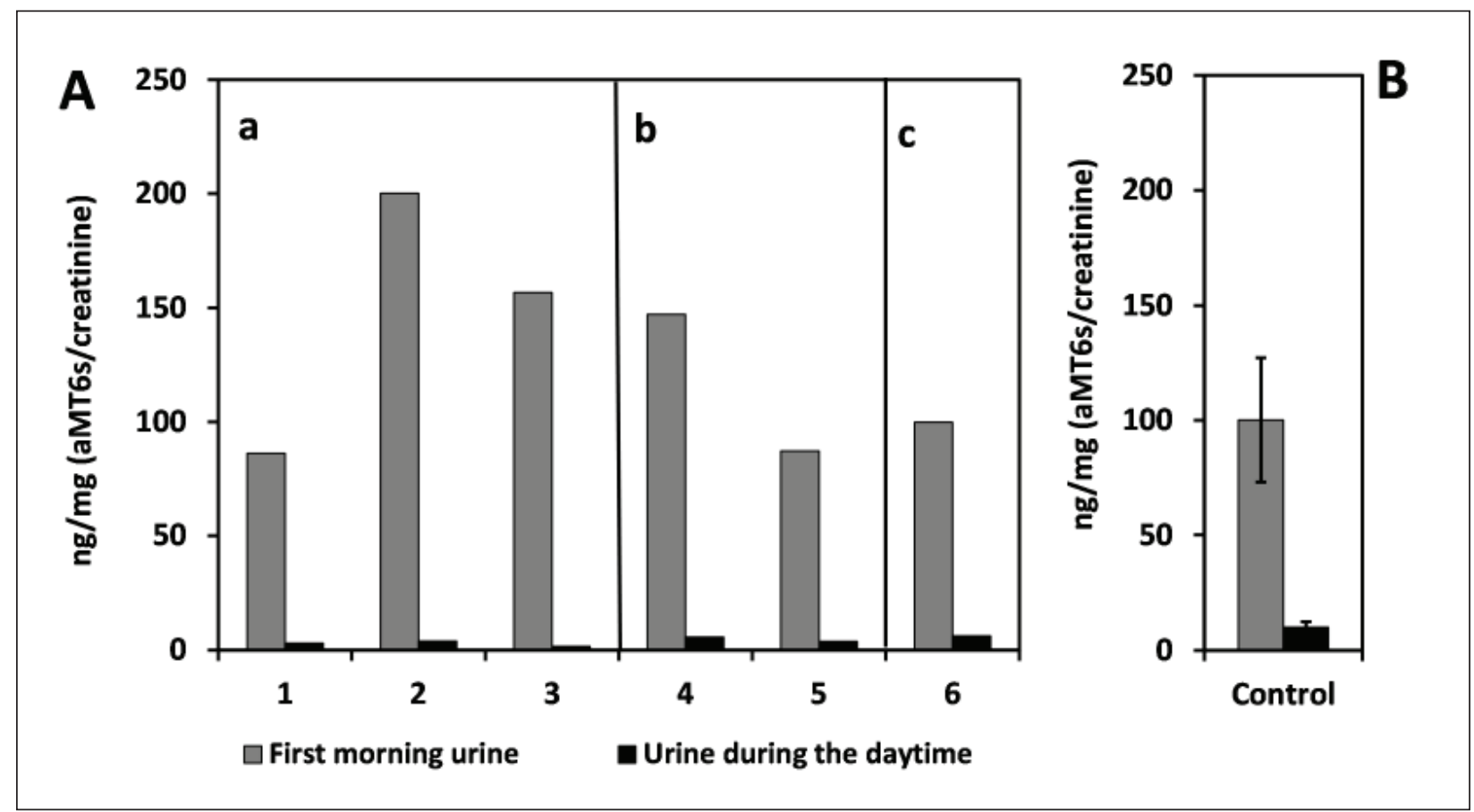

Figure 2. Concentrations of 6-sulphatoxymelatonin/creatinine (aMT6s) during 6 days in the first morning (gray bars) and afternoon urine (black bars) of 9 years old boy treated with intense blue light (A) during the night. Levels of aMT6s in urine of control boys $(B)$ are given as mean \pm SEM $(n=8)$. a - nights with phototherapy; $b$ - nights without phototherapy, $\mathrm{c}$ - night with subsequent phototherapy

It is generally accepted that melatonin biosynthesis can be effectively monitored by measurement of the urinary aMT6s, which represents a predominant metabolite of melatonin (Bojkowski et al. 1987b; Graham et al. 1998). Levels of melatonin metabolite in our study are in the line with the concentrations measured in published studies (Karasek 2004; Stebelova et al. 2015).

Treatment of hyperbilirubinemia in neonates with intense blue light is a common practice. However, there are surprisingly very limited data regarding the effects of this treatment on the melatonin production. The suppressed melatonin concentrations and decreased expression of clock genes Bmal1 and Cry1 were observed in the jaundiced neonates (Chen et al. 2005). The authors have recommended to set the time of the phototherapy to the day-time. In the present study, the young boy had to be treated during the night-time because of his daily school duties and activities. Our results demonstrated a clear day-night difference in the melatonin concentration, which was almost 50 times higher during the night- than the day-time.
Our data showed that when the eyes are sufficiently protected by the sleep mask, the rhythmic melatonin production is preserved and the melatonin may fulfill its physiological function in the synchronization of the circadian rhythms in humans. Moreover, our study does not support any extraocular circadian phototransduction in humans (Campbell and Murphy 1998), since the most parts of body were exposed to the intense blue light overnight. Taken together, our investigation suggests that the whole night treatment of hyperbilirubinemia with intense blue light has negligible side effects on the daily rhythm of the melatonin production, when the eyes are sufficiently protected by the sleep mask.

\section{Acknowledgments}

This publication is the result of the project implementation: Comenius University in Bratislava Science Park supported by the Research and Development Operational Programme funded by the ERDF. Grant number: ITMS 26240220086 and APVV0150-10. 


\section{References}

Bojkowski CJ, Aldhous ME, English J, Franey C, Poulton AL, Skene DJ, Arendt J. Suppression of nocturnal plasma melatonin and 6-sulphatoxymelatonin by bright and dim light in man. Horm Metab Res 19, 437-440, 1987a.

Bojkowski CJ, Arendt J, Shih MC, Markey SP. Melatonin secretion in humans assessed by measuring its metabolite, 6-sulfatoxymelatonin. Clin Chem 33, 1343-1348, 1987b.

Brainard GC, Sliney D, Hanifin JP, Glickman G, Byrne B, Greeson JM, Jasser S, Gerner E, Rollag MD. Sensitivity of the human circadian system to short-wavelength (420-nm) light. J Biol Rhythms 23, 379-386, 2008.

Campbell SS, Murphy PJ. Extraocular circadian phototransduction in humans. Science 279, 396-399, 1998.

Chen A, Du L, Xu Y, Chen L, Wu Y. The effect of blue light exposure on the expression of circadian genes: bmall and cryptochrome 1 in peripheral blood mononuclear cells of jaundiced neonates. Pediatr Res 58, 1180-1184, 2005.

Fox IJ, Chowdhury JR, Kaufman SS, Goertzen TC, Chowdhury NR, Warkentin PI, Dorko K, Sauter BV, Strom SC. Treatment of the Crigler-Najjar syndrome type I with hepatocyte transplantation. N Engl J Med 338, 14221426, 1998.

Graham C, Cook MR, Kavet R, Sastre A, Smith DK. Prediction of nocturnal plasma melatonin from morning urinary measures. J Pineal Res 24, 230-238, Erratum in: J Pineal Res 26, 128, 1999, 1998.

Hardeland R, Cardinali DP, Srinivasan V, Spence DW, Brown GM, Pandi-Perumal SR. Melatonin - a pleiotropic, orchestrating regulator molecule. Prog Neurobiol 93, 350-384, 2011.

Karasek M. Melatonin, human aging, and age-related diseases. Exp Gerontol 39, 1723-1729, 2004.

McIntyre IM, Norman TR, Burrows GD, Armstrong SM. Human melatonin suppression by light is intensity dependent. J Pineal Res 6, 149-156, 1989.

Stebelova K, Molcan L, Okuliarova M, Hanuliak P, Hartman P, Hraska J, Zeman M. The influence of indoor lighting with low blue light dose on urine 6-sulphatoxymelatonin concentrations and sleep efficiency of healthy volunteers. Biological Rhythm Research 46, 137-145, 2015.

West KE, Jablonski MR, Warfield B, Cecil KS, James M, Ayers MA, Maida J, Bowen C, Sliney DH, Rollag MD, Hanifin JP, Brainard GC. Blue light from light-emitting diodes elicits a dose-dependent suppression of melatonin in humans. J Appl Physiol (1985) 110, 619-626, 2011. 